spheric recording equipment, which is entirely automatic in operation, the cathode-ray direction finder for locating sources of atmospherics and the apparatus for measuring the strength of atmospheric noise on high and medium radio-frequencies.

\section{New Buildings}

The work of the Radio Research Station has hitherto been carried out in a number of temporary buildings which have been adapted with varying success to the needs of the research programme. With the expansion resulting from the Department's post-war programme, a permanent building has been designed by the architects of the Ministry of Works specifically to meet the research needs, and this building is now in course of erection. As will be seen from the accompanying photograph of a model (Fig. 1), the building will have at one end a twostory administrative block, together with all general services, workshops, stores, garages, dining room, etc., on the ground floor. The main portion of the building, containing the scientific laboratories, is of a single-story type with a backbone and four spurs, the ends of which open directly on to the field, which is regarded as a continuation of the laboratory space (Fig. 2). To make the best use of the field for experimental work, the building has been set to one side of the West Park, and every effort is being made to restrict the permanent metalwork in this and the other fields to the absolute minimum, so as to avoid any interference with the experimental work. A non-metallic pipe has been installed across the field to connect the waste outlet from the building with the main sewer, which itself is of non-metallic construction for the section across Ditton Park. The electric power supply for work in the field will be obtained by temporary connexion to one of a number of distribution outlets from a ring-main around the periphery. In order to reduce radio interference from the ignition systems of motor traffic to the minimum, the building is sited at a distance of more than 200 yards from the nearest public road; and most of the working parts of the fields in use are nearly half a mile from any major road carrying vehicular traffic.

Various huts of a temporary and transportable nature will also be used for field-work, the position of these over the land area available being determined by the nature of the experimental work, the size of the aerial systems required and the need to reduce mutual interference between investigations in the same vicinity. For special types of research, the use of isolated sites away from the Station will continue as in the past; and in some cases the work is conducted in various parts of the country in vehicles equipped as mobile laboratories. To facilitate the installation and calibration of apparatus in these, a covered space is provided at the end of each spur of the main building, so that the work can be conducted directly from the appropriate laboratory.

The present staff of the Radio Research Organization numbers just over a hundred. Most of these are now in temporary accommodation at Ditton Park ; due to the insufficiency of this accommodation, however, a small number still work at the National Physical Laboratory, Teddington. When the new building is ready for occupation, all the staff will be brought together at the Radio Research Station, and a steady increase in their numbers may be expected to take place over the next few years to deal with the expanding research programme.

\title{
BRISTOL MEETING OF THE BRITISH ASSOCIATION
}

$\mathrm{D}^{\mathrm{T}}$ URING the week August 31-September 7, the one hundred and seventeenth annual meeting of the British Association will be held in Bristol. This is the fifth occasion that the Association has met in Bristol, and all concerned with the arrangements are aiming at a meeting that will stand comparison with its predecessors.

Bristol was host to the British Association first in 1836, when Prof. Daubeny, of Oxford, addressed members on the progress of science during the previous year. In 1875 the presidential address by Sir John Hawkshaw, railway engineer and builder of the Severn Tunnel, was given in the Colston Hall, and considered whether nationalization of the railways might not be in the best interests of public safety and national economy. At one of the sectional transactions, Prof. Stanley Jevons read a paper "On the Progress of the Coal Question", concluding that "the coal famine of $1872-3$ may be regarded as the first twinge of the scarcity which must come ...".

'The third Bristol meeting was held in 1898 with Sir William Crookes as president. His address dealt first with world food supply, but went on to discuss progress in pure science, particularly in his own chief interest molecular physics, saying "the store drawn upon naturally by uranium and other heavy atoms only awaits the touch of the magic wand of science to enable the Twentieth Century to cast into the shade the marvels of the Nineteenth".

The president for the fourth Bristol meeting, in 1930, was Prof. F. O. Bower, who, with Dr. R. E.
Slade, showed how chemical science had helped to avert a world famine forecast by Sir William Crookes in 1898.

A brief glance at the preliminary programme will confirm that the high standard set by previous Bristol meetings has been maintained this year, and it will be interesting to see what new prophecies are forthcoming or what solutions have been found to age-old problems. 'This year's president, Sir Robert Robinson, is one of the world's greatest organic chemists, particularly noted for his research into the pigments of flowers and into the constitution of penicillin. At the inaugural general meeting he will speak on "Science and the Scientist", and as he is famed for being direct and candid, his audience at the Colston Hall can be assured of a lively and forthright address. During the week, as in past years, there will be television broadcasts of several items in addition to the usual sound broadcasts.

At the Colston Hall, the fourth to bear the name, and of them all the most perfect acoustically, there will be three evening discourses. The first of these will be given by Prof. C. F. Powell, of the University of Bristol, on "Experiments at Great Altitudes with Free Balloons", and will deal in part with nuclear physics in the very high-energy region. Prof. H. D. F. Kitto, professor of Greek in the University of Bristol, will give a discourse on "Scientific and Dramatic Modes of Thought", and Mr. B. J. C. Atkinson, of the Department of Prehistoric Archæology of the University of Edinburgh, will speak on "Stonehenge in the Light of Recent Research". 
Among the addresses by presidents of Sections, mention may be made of Prof. N. F. Mott's to Section $A$ on "The Physics of the Solid State", Sir Alexander Todd's to Section $B$ on "Nucleic Acid Structure and Function", Dr. D. B. Harden's to Section $H$ on "Anthropology : a Scientific Unity ?" and Mr. J. F. Wolfenden's to Section $L$ on "The Educated Man in 1955".

It is impossible to set out all the presidential addresses in this short article, or to mention in detail the many and varied subjects to be covered by the sixteen sections, but the programme contains something for everyone, scientist or layman-and possibly too much for the ardent enthusiast, who cannot hope to partake of all the fare provided. The sectional meeting rooms will be within short walking distances of the Reception Centre, and with one or two exceptions will be located in departments of the University. The reception room and administrative offices of the Reception Centre will be in the Victoria Rooms, which will also house an exhibition illustrating the work of the British North Greenland Expedition. Mr. R. A. Hamilton, chief scientist of the Expedition, will give a public afternoon lecture in the Colston Hall on "The Scientific Work of the British North Greenland Expedition", and other scientific members of the expedition will participate in the proceedings of certain sections. Another afternoon lecture to be given in the Colston Hall will be that by Mr. B. J. Mason, of the Department of Meteorology of the Imperial College of Science and Technology, London, on "Man's Influence on the Weather", dealing with progress and possibilities in weather modification.

In past years, scientific films have been shown at section meetings, and the last morning of the meeting has been devoted to the showing of films of scientific interest. This year, because of the interest shown ai recent meetings and in view of the increasing importance of the film in scientific work-not least as a medium for the interpretation of science to the layman-it has been decided, with the aid of the Scientific Film Association, to have daily continuous screenings of outstanding scientific films in sessions of about three-hours duration in a film studio at the College of Technology in Unity Street. These sessions will be on a "News Theatre" basis, and visitors will be at liberty to wander in-and out-whenever they please.

On two evenings the City Museum will be open to members who might wish to consult the curators or examine the extensive collections. While the collections refer primarily to the West of England, it should also be noted that the archæological objects include Egyptian antiquities with the emphasis on the pre-dynastic and early dynastic periods, and some fine Greek vases. The ethnographical collections include Maori tattooed heads and a bronze head from Benin. The geological gallery was unfortunately destroyed in an air-raid in 1940 ; but the Chaning Pearce and Tutcher collections, both of which are rich in Mesozoic fossils from the West Country, are worth noting. The Lewis Collection of Somerset birds' eggs and nests is outstanding, and there are extensive collections of British shells. Among the insect collections there are several of British Lepidoptera which are specially interesting, as also is the Barton collection of Buprestidae. The Bristol Naturalists' Society is arranging a special exhibition on the two evenings on which the City Museum is open. While in Bristol many members will undoubtedly visit the Blaise Castle House Folk Museum and Folk Park, situated in a magnificently wooded estate of some 400 acres. The Folk Museum is a branch of the City Museum and contains collections ranging from the fifteenth to the nineteenth centuries illustrating English social and cultural history, with especial reference to the West of England.

This year's visit of the Association coincides with the eight-hundredth anniversary of the granting of Bristol's first charter by King Henry II, and a special exhibition to mark the occasion will be displayed in the City Museum. In addition, Prof. David Douglas, professor of history in the University of Bristol, will comment on the granting of the charter in his Saturday evening lecture at the Colston Hall on "The Living Past" and will discuss the contribution to be made by historical studies to the progress of the arts and sciences.

Scientists like other mortals must needs eat, and the local executive committee is doing its utmost to anticipate and meet the demands of even the most fastidious. Provisional block bookings of accommodation in hotels and boarding houses in the City have already been made, and the accommodation in Wills Hall (a university hall of residence), three theological colleges, and the Y.W.C.A. and Y.M.C.A. hostels in the City have been reserved. Owing to the demand for hotel accommodation in Bristol, however, the block reservations cannot be held after June 30 unless a definite booking has been received by the hotel from the individual member.

On the lighter side, Bristol has done its best to compile an attractive programme of excursions, both general and sectional, covering a fairly wide area of the south-west. In and around Bristol, visits will be made to many places of archæological, historical and industrial interest, and several firms and organizations have generously come forward with offers of hospitality in various forms which will undoubtedly add to the success of the meeting. The steamer excursions should provide a wonderful opportunity for relaxation.

One may perhaps add here that, in common with the Association's hosts in other cities in recent years, the Bristol Local Executive Committee is at present producing a scientific survey of the region, the whole cost of which will be borne by the local fund and which will surely prove an informative and invaluable souvenir of the meeting. While the venue of this year's meeting is Bristol, it should not be forgotten that neighbouring authorities are also contributing, though necessarily to a lesser degree, to the success of the local arrangements. For example, the Schools Science Exhibition which members will see in the College of Technology would not have been possible without the whole-hearted co-operation of the local education authorities, particularly as the exhibits will have been staged during the holiday period. This is the first occasion on which such an exhibition has been arranged in connexion with an annual meeting of the British Association, and is an indication of the increasing interest in scientific achievements.

Of recent years Bristol has earned the reputation of being a 'City of Flowers'. During the period of the meeting the beautiful floral displays will be at their best in the parks, at the City Centre, in patches of loveliness by footpaths and in the streets, and in hundreds of window-boxes and hanging baskets. For spectacle and perfection, however, members should visit the annual horticultural show in the lovely natural setting of Durdham Downs during the first three days of the meeting. 